\title{
Assessing Environmental Externalities of Transportation Fuels
}

\author{
Dileep K. Birur, Robert H. Beach, Ross J. Loomis, \\ Michael P. Gallaher, and David C. Dayton
}

\section{Introduction}

Externalities can be defined as the inefficiencies that arise when some of the benefits accrue to or costs are imposed on individuals that are not directly involved in market agreements. In other words, externalities reflect positive (benefit) and negative (cost) implications on the well-being of one agent as a result of activities of another, external to the market mechanism. Among energy users, the transportation sector continues to play a prominent role because of its continued growth in energy consumption and its substantial economic and environmental externalities. This research brief, based on a research report ${ }^{1}$ from RTI's Energy Grand Challenge Initiative, highlights the environmental externalities of transportation fuels such as the impact on natural resources and greenhouse gas (GHG) emissions.

\section{Why the Transportation Sector?}

Oil has been the predominant source of energy for transportation with very limited and nascent alternatives. More than two-thirds of US oil consumption is in the transportation sector. Despite technological advancement to develop alternative fuels, use of petroleum products in the US transportation sector is likely to continue increasing. As estimated by the International Energy Agency (2011), 2 energy consumption by the US transportation sector is likely to increase from 29 quadrillion Btu (QBtu) in 2007 to 33 QBtu in 2035. GHG emissions from the US transportation sector account for $27 \%$ of national emissions, representing the second largest source after the electricity sector. ${ }^{1}$ To facilitate the assessment of environmental externalities, we developed a decision support mechanism based on economic models and a life-cycle assessment (LCA) model and estimated GHG emissions and biodiversity loss across different transportation fuels.

\section{Key Findings}

- Our estimates of the external cost of driving one thousand miles using different transportation fuels indicate that conventional gasoline generates a relatively higher cost ( $\$ 11.63 / 1,000$ miles) and use of $\mathrm{E}-85$ from woody biomass generates the lowest cost $(\$ 2.94 / 1,000$ miles).

- The impact of US biofuel policy on biodiversity loss due to land cover change was minimal.

- Water use in biofuels production is significantly higher than water use in petroleum fuels production.

- Research is needed to better understand the health risks associated with different transportation fuels.

\section{Life-Cycle Assessment}

The LCA models help analysts evaluate a product at all stages of its life. The LCA approach helps assess the environmental impacts of transportation fuels in a comprehensive way. Several LCA models exist for assessing GHG emissions of transportation fuels, but they vary widely in terms of assumptions, coverage of different types of fuels and parameter values used, for example. We reviewed several LCA models keeping in mind the coverage of transportation fuels. We selected the GREET model for this study because of its depth of coverage of energy feedstock and fuel pathways. The GREET model was developed by Argonne National Laboratory (2009) ${ }^{3}$ to assess and compare the GHG emissions across different transportation fuels using the attributional approach of LCA. Though the GREET model allows for comparisons of the emissions and energy sources of a variety of alternative feedstocks, it does not attempt to monetize the external costs of these emissions. For this study, we assigned estimates of the social cost of GHG emissions as well as the cost of degraded air quality from other regulated emissions reported in GREET. For valuation of the effects of GHG emissions, we 
used the estimates of the social cost of carbon developed for US regulatory impact analyses. ${ }^{4}$ These estimates are based on multiple projections of the impact of climate change on global economic output and are sensitive to the time frame of analysis and discount rate. We applied their social cost estimate of $\$ 21.4$ per ton of $\mathrm{CO}_{2}$ equivalent for 2010 with a 3\% discount rate. 4

\section{Models Used in this Analysis}

- Greenhouse Gases, Regulated Emissions and Energy Use in Transportation (GREET) model-used for estimating life cycle-based GHG emissions.

- Forest and Agriculture Sector Optimization ModelGreenhouse Gas Emissions (FASOM-GHG) — a dynamic partial equilibrium model used to estimate the impact of US regional-level variations in crop yields and inputs.

- Air Pollution Emission Experiments and Policy (APEEP) model —an integrated assessment model used for estimating monetary damages.

- Global Trade Analysis Project-Biofuels (GTAP-BIO) model-a computable general equilibrium model used for estimating global land-use land-cover impacts of US biofuels production.

- Open Source Impacts of REDD+ (Reducing Emissions from Deforestation and Forest Degradation) Incentives Spreadsheet (OSIRIS) model-a global partial equilibrium model that simulates deforestation rates, emissions, biodiversity loss, and REDD revenue.

\section{Impact on Air}

To estimate the cost of degraded air quality from the non-GHG emissions reported in GREET, we used the estimates generated by the APEEP analysis model. ${ }^{5}$ The APEEP analysis model is an integrated assessment model that connects emissions of air pollution through air quality modeling to exposure, physical effects, and monetary damages. The model calculates the marginal damage of emissions for about 10,000 distinct sources of air pollution and for six pollutants: $\mathrm{NH}_{4}, \mathrm{PM}_{2.5}$, $\mathrm{PM}_{10}, \mathrm{NO}_{\mathrm{X}}, \mathrm{SO}_{\mathrm{X}}$, and volatile organic compounds (VOCs). APEEP includes six categories of criteria air pollution damages related to human health and eight categories of physical impacts such as materials damage, ozone damage to crops and forests; the cost of foregone recreation due to $\mathrm{SO}_{2}, \mathrm{NO}_{\mathrm{x}}$, ozone, and VOCs; and the cost of reduced visibility due to airborne particulate matter.

To transform costs reported in APEEP to national estimates, we weighted the county-level cost estimates by the 2010 county populations. Based on the population-weighted cost of regulated air emission values and the emissions estimates reported in GREET, driving 1,000 miles using conventional gasoline generates external costs of $\$ 11.63$ (Figure 1). The lowest external cost of alternative fuels is estimated to be $\$ 2.94$ per 1,000 miles from an $85 \%$ ethanol blend (E-85) using woody biomass, such as hybrid poplar, as a feedstock. Fuels relying on coal as a significant input in production, such as diesel produced using the Fischer-Tropsch process (\$27.24/1,000 miles), impose greater external costs than conventional gasoline or conventional diesel (\$9.74/1,000 miles).

\section{Figure 1. Valued externalities of alternative fuels $(2007 \$ / 1,000$ miles)}

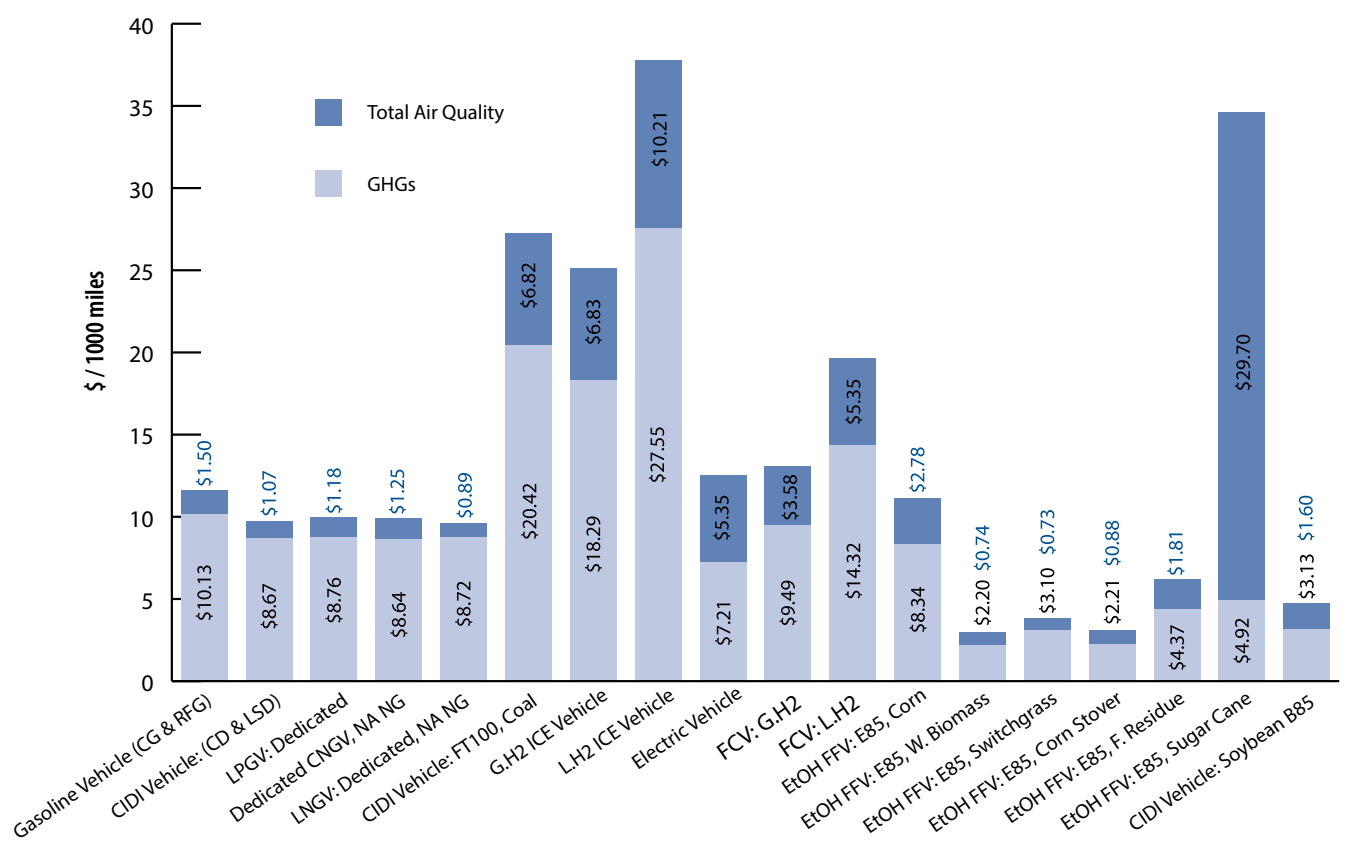

Source: Birur et al. (2013). ${ }^{1}$ 
For certain feedstocks, regional variation in yields and crop inputs may result in externalities that vary by region. To explore the potential differences, we created a spreadsheetbased tool to change the corn-based ethanol inputs within GREET by region. The crop input budgets were based on FASOM-GHG, a dynamic partial equilibrium model used mainly for agriculture- and forestry-related environmental policy analyses. ${ }^{6}$ Based on our analysis, regional differences in corn production did not result in large differences in values of GHG emissions. Ethanol produced using corn from the Great Lakes region is estimated to have the lowest life-cycle GHG emissions, while ethanol produced using corn from the Pacific Southwest is estimated to have the highest. For corn-based ethanol, differences in life-cycle GHG emissions based on the feedstock regions were insignificant. The GHG emissions from the Pacific Southwest were only $7 \%$ greater than those from the Great Lakes states.

\section{Impact on Biodiversity}

A large-scale expansion in biofuels production to meet the demand for feedstock crops leads to a combination of shifts in cropping patterns on the existing cropland and conversion of forest or pasture land into new cropland. Increasing crop prices transferred around the world through international trade linkages could result in similar land conversion in other countries, which is known as indirect land use change (iLUC). Land converted from forest or pasture cover leads to additional GHG emissions as a result of the release of carbon stock from the soil and biomass. Accounting for iLUC-related emissions in assessing the biofuels for policy making has been a highly contentious issue. In addition to GHG emissions, this iLUC has other consequences on the environment such as a loss of biodiversity.

To estimate the potential magnitude of biodiversity loss associated with the US renewable fuel policy, we used modelpredicted global forest cover change due to US renewable fuels policies from the GTAP-BIO model. ${ }^{1}$ The GTAP-BIO model is a global computable general equilibrium model with a focus on biofuels and land use change. We implemented three separate policy scenarios in the GTAP-BIO model: (1) incremental production of corn ethanol in the United States increasing to 15 billion gallons by 2015, (2) soybean biodiesel to 1 billion gallons, and (3) import of sugarcane ethanol to 1.5 billion gallons. When biofuels production increases in the model, the price of crops increases, leading to increased feedstock crops production, which further leads to shifts in cropping patterns within the existing cropland and conversion of other land types such as pasture or forest cover to meet any additional demand for cropland. The market equilibrium is the net result of demand for food and feed, as well as fuel.
The resulting changes in global land cover based on the individual biofuels production from the GTAP-BIO model were incorporated into the OSIRIS ${ }^{7}$ model. The OSIRIS model is generally used to evaluate impacts of different REDD scenarios on biodiversity on a global scale and also to optimize biodiversity. We used estimates of national forest cover and endemic forest dwelling species from OSIRIS to estimate the potential biodiversity loss across 85 countries. We estimated the loss of species of amphibians, birds, and mammals as a result of changes in forest cover within OSIRIS using the species-area curve. ${ }^{8}$ The species-area relationship includes country-specific species committed to extinction, current number of forest species in the country, and annual deforestation rate. Our estimates of biodiversity impacts of US biofuels production were minimal across all countries, except for Brazil. The greatest impact on biodiversity was found to take place in Brazil. However, the predicted number of species extinctions was below 0.04 even when sugarcane ethanol is imported into the United States. Though the aggregate measure of species extinction has some caveats compared with spatially disaggregated forest loss, the OSIRIS results give a broader picture of the potential impact of policies such as biofuel mandates, which are suspected to affect biodiversity on a global scale.

\section{Impact on Water Use}

With the growing number of national policies aimed at achieving energy security and reducing environmental and other externalities by developing alternative fuels, the impacts of these new technologies on water use are drawing greater attention from researchers. Until recently, most of the debates on the food vs. fuel issue focused on diverting food grains and cropland to biofuels production. With the rising interest in accelerating the production of unconventional fuels such as shale gas, the dimension of diverting water from farm production to hydraulic fracturing of oil shale has been added to the food vs. fuel debate surrounding expanded use of renewable fuels. Using LCA, studies have estimated that a gallon of corn-ethanol production requires a minimum of 10 gallons of water mainly depending on the agro-climatic conditions of the feedstock growing region and the soil type. In contrast, water consumption in the gasoline life-cycle ranges from 3.6 to 6.6 gallons. ${ }^{1}$ This water is incurred mainly during the oil recovery process depending on the type and source of crude, recovery technology, geological condition, the age of the well, and water reinjection. A similar range of water use is observed in oil-sands recovery. Though biofuels production was found to require a substantial volume of water, most of it is consumed during feedstock production, and only a comparably small volume is required by biofuel processing plants. ${ }^{1}$ Recent advancement in commercial shale energy 


\section{Environmental Externalities}

exploration in the United States indicates that 1 gallon of oil shale requires 1 to 12 gallons of water throughout the life cycle of oil shale production. ${ }^{1}$ However, more research is needed on the impact of shale energy extraction on groundwater quality and its interaction with surface water.

\section{Impact on Public Health}

Studies of human health effects of different transportation fuels are scanty. Though reductions in GHG emissions from alternative renewable fuels are expected to produce health benefits, some studies contradict this view. Literature findings based on atmospheric simulation models suggest that emissions from E85 may increase ozone-related mortality, hospitalization, and asthma by about $4 \%$ compared with emissions from $100 \%$ gasoline in the United States. ${ }^{1}$ However, other studies indicate that biofuels have health risks comparable to or less than their counterparts derived from petroleum. ${ }^{1}$ Further research on health effects across different fuels in a consistent manner would significantly contribute to an overall understanding of the transportation sector.

\section{Conclusions}

Studies of environmental externalities of transportation fuels, particularly in recent years, have focused heavily on alternative fuels, without evenly accounting for the externalities of petroleum fuels. The decision support mechanism developed based on LCA and economic models indicated that the external cost across different fuels of driving a thousand miles is cheapest using E-85 from woody biomass. The GTAP-BIO model-based deforestation rates due to implementing US RFS2 policies for first-generation biofuels, when applied to the OSIRIS model, indicated a minimal biodiversity loss. Apart from these environmental externalities, the impacts on water use and human health are also crucial in assessing transportation fuels, and further research is needed in this area. These estimates would help researchers understand if a particular transportation fuel technology meets the present energy needs, without compromising the ability of future generations to meet their own needs. Given this, it is important to apply sustainability standards to not only transportation fuels, but also to other energy sectors. Greater use of domestically produced sustainable alternative fuels would also help in achieving energy security.

\section{References}

1 Birur DK, Beach RH, Loomis RJ, Chipley S, Gallaher MP, Dayton DC. Externalities of transportation fuels: assessing trade-offs between petroleum and alternatives. RTI Press publication No. OP0013-1307. Research Triangle Park, NC: RTI Press; 2013. Available from: http://www.rti.org/rtipress
2 International Energy Agency. World energy outlook-2011. Paris, France: International Energy Agency; 2011. Available from: http:// www.worldenergyoutlook.org/

3 Argonne National Laboratory (ANL). Greenhouse Gases, Regulated Emissions, and Energy Use in Transportation (GREET) computer model, GREET 1.8 c. Argonne National Laboratory, Argonne, IL; 2009. Available from: http://greet.es.anl.gov/main

4 Interagency Working Group on Social Cost of Carbon. Technical support document: social cost of carbon for regulatory impact analysis under Executive Order 12866; 2010. Available from: http:// www.epa.gov/otaq/climate/regulations/scc-tsd.pdf

5 Muller N, Mendelsohn R. The Air Pollution Emission Experiments and Policy Analysis Model (APEEP). New Haven, CT: School of Forestry and Environmental Studies, Yale University; 2006. Available from: http://www.econ.yale.edu/ nordhaus/Resources/ muller_JEEM_Appendix.pdf

6 Adams D, Alig R, McCarl BA, Murray BC. FASOMGHG conceptual structure, and specification: documentation. Unpublished paper. College Station, TX: Texas A\&M University; 2005. Available from: http://agecon2.tamu.edu/people/faculty/ mccarl-bruce/papers /1212FASOMGHG_doc.pdf

7 Busch J, Strassburg BA, Cattaneo R, Lubowski A, Bruner R, Rice A, Creed R, Ashton FB. Open Source Impacts of REDD+ Incentives Spreadsheet (OSIRIS v3.4). Arlington, VA: Conservation International; 2010. Available from: http://www.conservation.org/ osiris/Pages/overview.aspx

8 Kissinger G. The link between reducing deforestation and forest degradation and biodiversity conservation. Vancouver, BC: Lexeme Consulting; 2010. Available from: http://assets.wwf.no/downloads/ redd_biodiversity_report_technical_background.pdf

\footnotetext{
About the Authors

Dileep K. Birur, PhD, is a research economist in the Agriculture, Resource \& Energy Economics and Policy (AREEP) Program at RTI International.

Robert H. Beach, PhD, is director of the AREEP Program at RTI.

Ross J. Loomis, MS, is a senior economist in RTI's Ecosystem Services Research Program.

Michael P. Gallaher, PhD, is the senior director of RTI's Center for Environmental, Technology, and Energy Economics.

David C. Dayton, PhD, manages the Biofuels Program in RTI International's Energy and Technology Unit.

RTI Press Research Briefs and Policy Briefs are scholarly essays on policy, methods, or other topics relevant to RTI areas of research or technical focus.

RTI International, 3040 East Cornwallis Road, PO Box 12194 Research Triangle Park, NC 27709-2194 USA

919.541.6000_rtipress@rti.org www.rti.org

O2013 Research Triangle Institute. RTI International is a trade name of Research Triangle Institute.

All rights reserved. This brief is protected by copyright. Credit must be provided to the author and source of the document when the content is quoted. Neither the document nor partial or entire reproductions may be sold without prior written permission from the publisher.

RTI Press publication RB-0004-1306

doi:10.3768/rtipress.2013.rb.0004.1306

www.rti.org/rtipress
} 